\title{
HEAD INJURIES IN INFANTS: A CLOSER LOOK AT BABY-WALKERS, STAIRS AND NURSERY FURNITURE
}

\author{
Jane Elkington* \\ Injury Prevention Coordinator \\ NSW Department of Health
}

Suzanne Blogg $\dagger$

Public Health Officer

NSW Public Health Officer Training Program

\section{Jenny Kelly}

Research Director, AC Nielsen (Research)

Victor Carey

Director, Childsafe NSW

This article describes the methods and findings of an analytical study of potential risk and protective factors for infants presenting with head injuries to emergency departments of seven hospitals in NSW. The Injury Prevention Policy Unit, NSW Department of Health, conducted a case-control study that examined babywalkers, stairs and nursery furniture. The incentive for the study came from a national discussion paper on the safety of baby-walkers, which raised options for action for improving the devices by consumer safety organisations. It was apparent from the paper and from subsequent discussions that ongoing indecisiveness about appropriate action to take on baby-walkers was due largely to the lack of evidence about the injury risks they pose to infants. ${ }^{1}$

Injuries associated with baby-walkers usually involve infants aged less than 12 months. ${ }^{2}$ It has been estimated that 31 to 50 per cent of children using walkers will have an injury in them..$^{3-5}$ The most common injuries associated with baby-walkers are head injuries that result from falling down stairs. ${ }^{6-10}$

While there are many descriptive or case-series studies in the literature about injuries associated with baby-walkers, to date there are no reported analytical studies that provide evidence about whether baby-walkers increase the risk of injury.

\section{METHOD}

A case-control study design was selected that enabled the investigation of 'exposures' in the homes of children who had sustained head injuries compared with a similar group that had not been injured. Through this analytical design, baby-walkers, stairs, nursery furniture and safety devices such as stair guards and safety straps could be examined to see whether they increase the risk of a head injury (risk factors), decrease the risk (protective factors), or show no association.

\footnotetext{
* Currently a freelance Public Health Consultant.

$\dagger$ Currently at the National Centre for Epidemiology and Population Health, Australian National University.

$\ddagger$ Currently Director, Mid North Coast Public Health Unit.
}

The study involved a retrospective telephone survey conducted between December 1994 and February 1995 with the parents of the infants who were either 'cases' or 'controls'. Cases were 93 infants between the ages of six and 12 months who presented with trauma to the face or head between August 1993 and November 1994 to one of seven NSW emergency departments that participate in the Childsafe Injury Surveillance System. Infants whose injury was due to motor vehicle trauma or was suspected to be associated with child abuse were excluded from this group. Infants for whom the respondent/caregiver indicated during the telephone interview that the child had not incurred a head injury during the study interval were subsequently excluded. Controls were 268 infants matched to the case infants on age (identified through the use of birth records from the same hospitals or nearby maternity hospitals) but who had not incurred a medically attended head injury between the ages of six and 12 months.

\section{FINDINGS}

Some of the significant findings were:

- After statistically controlling for socio-economic differences between the two groups of subjects (injured and non-injured), the presence of longer flights of stairs (six or more steps) in a household was the strongest predictor of head injury in the infants (odds ratio $[\mathrm{OR}]=1.33, \mathrm{p}=0.05$ ).

- In homes where baby-walkers were used and stairs were present, the risk of head injury to infants was 3.5 times greater if no stair guards or barriers were used than if they were used all the time $(\mathrm{OR}=3.53,95$ per cent $\mathrm{CI}=1.21-10.30$ ).

- As shown in Table 3, those infants who used babywalkers more frequently $(\mathrm{OR}=2.47,95$ per cent $\mathrm{CI}=0.97-6.48)$ and those who commenced using them at a younger age, were significantly more likely to have incurred a head injury during the study interval $(\mathrm{OR}=3.02,95$ per cent $\mathrm{CI}=1.01-9.65)$.

The preferred location for nappy changes was associated with significant differences between the injured cases and the control group. A higher proportion of cases (56 per cent) than controls ( 42 per cent) were changed on a table or bench rather than on items lower to the ground such as a bed, couch or the floor itself. $(\mathrm{OR}=1.77,95$ per cent $\mathrm{CI}=1.07-2.92)$. Furthermore, of those who used a nappy change location above the floor, significantly more controls ( 26 per cent) than cases (19 per cent) reported always using a safety strap or harness. The use of the safety strap appeared to reduce the chance of incurring a head injury by two-thirds $(\mathrm{OR}=0.33,95$ per cent $\mathrm{CI}=0.15$ 0.69 ). 


\section{TABLE 3}

COMPARISON OF CASES AND CONTROLS ON FACTORS RELATED TOTHE USE OF BABYWALKERS AND OTHER NURSERY PRODUCTS WHEN THE INFANTS WERE 6 TO 12 MONTHS OLD

\begin{tabular}{|c|c|c|c|c|}
\hline Information about nursery product use & Cases, \% & Controls, \% & Odds ratio & $95 \% \mathrm{Cl}$ \\
\hline Ever used a baby-walker & 39 & 43 & 0.83 & $0.50-1.38$ \\
\hline \multicolumn{5}{|l|}{ Of those who used a baby-walker: } \\
\hline started using it before 8 months of age & 86 & 67 & $3.02^{*}$ & $1.01-9.65$ \\
\hline used it at least most days & 78 & 59 & 2.47 & $0.97-6.48$ \\
\hline used it two or more hours/day & 44 & 33 & 1.36 & $0.60-3.07$ \\
\hline \multicolumn{5}{|l|}{ Of those with stairs and used walker: } \\
\hline did not use stair guards or barriers & 33 & 12 & $3.53^{*}$ & $1.21-10.30$ \\
\hline $\begin{array}{l}\text { Used high chair twice/day or more } \\
\text { If used high chair: }\end{array}$ & 75 & 66 & 1.56 & $0.89-2.77$ \\
\hline reported always using strap/harness & 83 & 76 & 1.47 & $0.73-2.98$ \\
\hline $\begin{array}{l}\text { Main nappy change location a bench or table } \\
\text { If nappy changed above floor: }\end{array}$ & 56 & 42 & $1.77^{*}$ & $1.07-2.92$ \\
\hline reported always using safety strap & 19 & 26 & $0.33^{*}$ & $0.15-0.69$ \\
\hline Used stroller/pram at least once most days & 63 & 68 & 1.26 & $0.72-2.21$ \\
\hline $\begin{array}{l}\text { Stroller of lightweight, collapsible or umbrella style } \\
\text { If used stroller/pram: }\end{array}$ & 42 & 38 & 1.21 & $0.73-2.02$ \\
\hline reported always using strap/harness & 90 & 91 & 0.96 & $0.41-2.32$ \\
\hline \multicolumn{5}{|c|}{$\begin{array}{l}\text { * Statistically significant, indicated by the confidence interval not including a value of } 1.00 \text {. } \\
\text { † This includes: change tables, table or desk tops, bench tops, or dressing tables. These items tend to be higher } \\
\text { than all other options such as bed or couch, knee, chair or toilet and the floor. }\end{array}$} \\
\hline
\end{tabular}

\section{DISCUSSION}

There are some limitations in the study data. One of those was that the majority of injuries were of a minor nature, which may blur the distinction between the two groups of study subjects. Another was an over-representation among the cases of parents with indicators of higher socioeconomic status (significantly higher household income and significantly higher proportion who had completed Year 12 or HSC). This group may be more comfortable with accessing the health care system and more disposed to seek medical care for any (including minor) head injuries. These limitations should be considered for their potential to bias the findings of this study. Nevertheless, the study is most valuable in providing analytical evidence not yet reported elsewhere in the literature that baby-walkers, when used frequently over an extended period of a child's early development, particularly in houses with flights of stairs, may increase the risk of a head injury. These results confirm long-standing warnings by health professionals about the dangers of baby-walkers. The study also provides confirmation of the value of safety devices such as stair guards and safety straps.

\section{REFERENCES}

1. Federal Bureau of Consumer Affairs, Trade Practices Act 1974; Part V, Division 1A. Consumer Safety, Need for Mandatory Action: Baby Walkers, August, 1993.

2. Partington MD. Head injury and the use of baby walkers: A continuing problem. Ann Emerg Med 1991; 20: 652-654.

3. Kavanagh CA, Banco L. The infant walker: A previously unrecognised health hazard. Am J Dis Child 1982; 136: 205-206.

4. Board of Trustees, American Medical Association. Use of infant walkers. Am J Dis Child 1991; 145: 933-934.

5. Frazen LE, Felizberto PI. Baby walker injuries. Pediatrics 1982; 70: 106-109.

6. Chiaviello CT, Christoph RA, Bond GR. Infant walker-related injuries: A prospective study of severity and incidence. Pediatrics 1994; 93(6): 974-976.

7. Reider MJ, Schwartz C, Newman J. Patterns of walker use and walker injury. Pediatrics 1986; 78(3): 488-493.

8. Coats TJ, Allen M. Baby walker related injuries: A continuing problem. Ann Emerg Med 1991; 8: 52-55.

9. Moller J. Baby walkers: An attempt to assess injury risk compared with some other nursery products. National Injury Surveillance Unit (SA, Australia), Adelaide, 1994, unpublished.

10. Watson WL, Ozanne-Smith J, Begg S, Imberger A, Ashby $\mathrm{K}$, Stathakis V. Injuries associated with nursery furniture and bunk beds. Melbourne: Monash University Accident Research Centre, Report No. 123, October, 1997.

Copies of the report on this study, Baby-Walkers, Stairs and Nursery Furniture as Potential Risk Factors for Head Injuries in Infants: A Case-Control Study, is available from the Better Health Centre, (02) 9816 0452. Please quote State Publication Number HP 980064. 